\title{
The Yersinia Type III secretion effector YopM Is an E3 ubiquitin ligase that induced necrotic cell death by targeting NLRP3
}

\author{
Congwen Wei ${ }^{1,5}$, Ying Wang ${ }^{1,5}$, Zongmin $\mathrm{Du}^{2,5}$, Kai Guan ${ }^{1}$, Ye Cao ${ }^{1}$, Huiying Yang ${ }^{2}$, Pengyu Zhou ${ }^{1,4}$, Feixiang $\mathrm{Wu}^{4}$, Jiankang Chen ${ }^{1,3}$, \\ Penghao Wang ${ }^{1}$, Zirui Zheng ${ }^{1}$, Pingping Zhang ${ }^{1}$, Yanhong Zhang ${ }^{1}$, Shengli Ma ${ }^{1}$, Ruifu Yang ${ }^{*, 2}$, Hui Zhong ${ }^{*, 1}$ and Xiang He ${ }^{*, 1}$
}

Yersinia pestis uses type III effector proteins to target eukaryotic signaling systems. The Yersinia outer protein (Yop) M effector from the $Y$. pestis strain is a critical virulence determinant; however, its role in $Y$. pestis pathogenesis is just beginning to emerge. Here we first identify YopM as the structural mimic of the bacterial IpaH E3 ligase family in vitro, and establish that the conserved CLD motif in its N-terminal is responsible for the E3 ligase function. Furthermore, we show that NLRP3 is a novel target of the YopM protein. Specially, YopM associates with NLRP3, and its CLD ligase motif mediates the activating K63-linked ubiquitylation of NLRP3; as a result, YopM modulates NLRP3-mediated cell necrosis. Mutation of YopM E3 ligase motif dramatically reduces the ability of $Y$. pestis to induce HMGB1 release and cell necrosis, which ultimately contributes to bacterial virulence. In conclusion, this study has identified a previously unrecognized role for YopM E3 ligase activity in the regulation of host cell necrosis and plague pathogenesis.

Cell Death and Disease (2016) 7, e2519; doi:10.1038/cddis.2016.413; published online 8 December 2016

Inflammatory reactions in response to pathogen infection are orchestrated by complex soluble mediators, including locally released cytokines and chemokines, such as IL- $1 \beta$ and IL-18. ${ }^{1-4}$ The activation of caspase- 1 is essential for the processing of pro-IL-1 $\beta$ and pro-IL-18 and the secretion of their mature biologically active forms. ${ }^{5}$ A critical step in the activation of caspase- 1 is the assembly of a large protein complex (inflammasome) containing the NOD-like receptors (NLRs), adapter ASC, and pro-caspase-1. ${ }^{6}$ The inflammasome recognizes intracellular damage-associated molecular patterns (DAMPs) derived from pathogens by cytosolic NLRs. ${ }^{7}$ NLRs undergo oligomerization in response to DAMP recognition and recruit ASC by PYD-PYD interaction. ${ }^{8,9}$ Subsequently, pro-caspase-1 is recruited through the C-terminal caspase recruitment domain (CARD) of ASC, which is essential for its activation. ${ }^{10-13}$

The best-characterized inflammasome is the NOD-like receptor (NLR)-family pyrin domain-containing 3 (NLRP3, also known as Nalp3 or cryopyrin) inflammasome, which can be activated by a wide range of stimuli. ${ }^{14-18}$ Two different types of NLRP3-dependent cell death have been reported. ${ }^{19}$ Pyroptosis is an inflammatory program of cell death, which is caspase-1-dependent. ${ }^{10}$ Activation of pyroptosis promotes innate immune responses, protects against numerous pathogens, and enables clearance of invading pathogens. Therefore, evasion of NLRP3-induced pyroptosis is an important strategy of pathogen. ${ }^{20,21}$ For example, Kaposi's sarcoma-associated herpes virus encodes an NLRP1 homolog that lacks PYD and CARD domain, which can competently interact with host NLRP3 and inhibits virally induced pyroptosis. $^{22}$

Recent works have implicated the role of NLRP3 in triggering necrosis, which is another form of pathogeninduced cell death independent of caspase-1. Although necrosis induction eliminates pathogen by removal of infected cells, it also leads to exacerbated inflammation and sepsis. In necrotic cells, HMGB1 is passively released into the cytoplasm and extracellular space, where it serves as a useful necrosis indicator and late proinflammatory molecule. HMGB1 has also been suggested to act as an amplifier of neutrophil recruitment, injury amplification, and host lethality. ${ }^{23}$ For example, HMGB1 is released during dengue hemorrhagic fever and dengue shock syndrome, impacting on disease pathogenesis. ${ }^{24}$ Shigella flexneri causes NLRP3-dependent necrosis and HMGB1 release in macrophages associated with further tissue damage. ${ }^{25}$ Yersinia pestis infection can also induce macrophage necrosis, which is dispensable for innate host resistance but contributes to enhanced cytotoxicity. ${ }^{26}$ However, the role of NLRP3-dependent necrosis in $Y$. pestis pathogenesis remains further investigation.

YopMs, one of the T3SS effectors of pestis, are composed of a variable number of 20 or 22 amino acid (aa) leucine-rich repeats (LRRs), which are known to mediate protein-protein interactions. ${ }^{27-30}$ YopM has a nuclear localization signal in

\footnotetext{
${ }^{1}$ State key Laboratory of Pathogen and Biosecurity, Beijing Institute of Biotechnology, Beijing, China; ${ }^{2}$ State key Laboratory of Pathogen and Biosecurity, Beijing Institute of Microbiology and Epidemiology, Beijing, China; ${ }^{3}$ The General Hospital of Chinese People's Armed Police Forces, Beijing, China and ${ }^{4}$ Department of Hepatobiliary Surgery, Affiliated Tumor Hospital of Guangxi Medical University, Nanning, China

*Corresponding author: R Yang or $\mathrm{H}$ Zhong or X He, State key Laboratory of Pathogen and Biosecurity, Beijing Institute of Biotechnology, Beijing 100850, China, Tel: +86 0106694 8595; Fax: +86 01066948594 or Tel: +86 0106693 1809; Fax: +86 01066931821 or Tel: +86 01066931809 ; Fax: +86 01066931821 ; E-mail: ruifuyang@gmail.com or towall@yahoo.com or hexiang_spring@yahoo.com

${ }^{5}$ These authors contributed equally to this work.

Received 07.5.16; revised 09.11.16; accepted 11.11.16; Edited by J Chipuk
} 
a
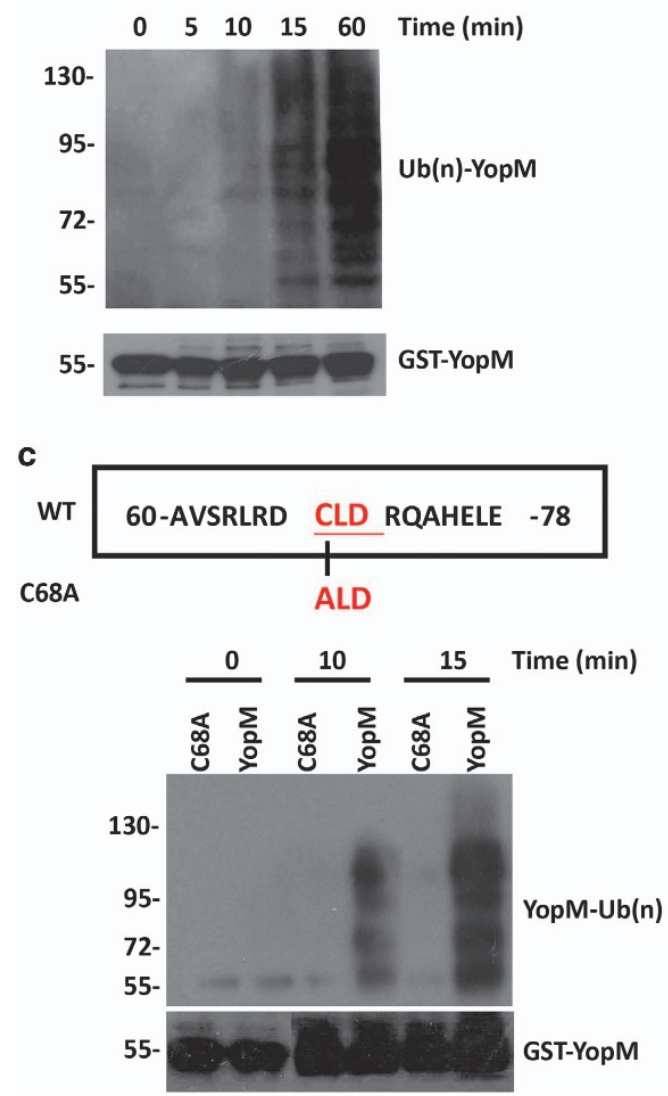

b
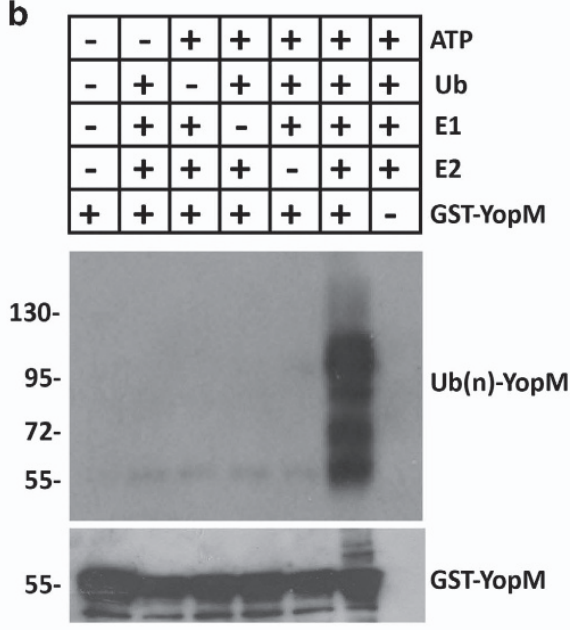

Figure 1 Y. pestis T3SS YopM is an E3 ubiquitin ligase. (a and $\mathbf{b})$ Immunoblotting showing autoubiquitination by GST-YopM in the presence (a) or absence (b) of E1 and E2, ATP, and Ub. (c) Effects of mutations of Cys 68 on YopM-catalyzed polyubiquition chain synthesis. Ubiquitination assays were carried out using GST-YopM and GST-YopM C68A. All cell-based experiments were performed independently two to three times with comparable results

its C-terminus, and is translocated into the nucleus via an endocytic pathway. ${ }^{31-33}$ The first identified targets of YopM were ribosomal S6 protein kinase 1 (RSK1) and protein kinase C-like 2 (PRK2). ${ }^{34}$ LRR6 to LRR15 region of YopM is required for PRK2 binding, while C-terminal domain (299-409 aa) is required for binding to RSK1. ${ }^{35}$ Deletion of either of these domains from YopM abrogates the virulence of $Y$. pseudotuberculosis via the orogastric route of infection. ${ }^{36}$ One recent report indicated that YopM is a potent antagonist of both caspase-1 activity and activation. ${ }^{37}$ While all other Yops have been shown to possess enzymatic activity, the YopM protein is believed to be devoid of catalytic activity.

Here we demonstrate that YopM is an E3 ubiquitin ligase with a novel enzyme active site in its $\mathrm{N}$-terminal, which can regulate NLRP3 expression. The conserved CLD motif in the $\mathrm{N}$-terminal of YopM mediates the activating K63-linked ubiquitylation of NLRP3. Mutation of YopM E3 ligase motif (C68A mutant) not only abolishes YopM-induced NLRP3 stabilization but also dramatically reduces the ability of $Y$. pestis to stimulate NLRP3-mediated HMGB1 release and cell necrosis. Thus our results identify a previously unrecognized role for YopM in the regulation of NLRP3-mediated necrosis signaling and plague pathogenesis.

\section{Results}

Y. pestis T3SS YopM is an E3 ubiquitin ligase. Recent study reported that a CXD catalytic motif in the bacterial pathogen Shigella flexneri could function as an E3 ligase. ${ }^{38}$ Subsequent analysis of the amino acid sequences of YopM revealed a conserved CLD motif (C68/L69/D70) in the $\mathrm{N}$-terminal domain, which we hypothesized may function as an novel E3 catalytic domain (Supplementary Table S1). To test this hypothesis, a purified GST-YopM fusion protein was used for autoubiquitination activity assay in the presence of ATP, ubiquitin, E1 and E2 in vitro. We detected molecular species $7 \mathrm{kDa}$ larger than corresponding YopM fragments within $10 \mathrm{~min}$ of the ubiquitination reaction, and larger species accumulated thereafter (Figure 1a). In accordance with E3 ligase activity, no such species were detected even after $1.5 \mathrm{~h}$ of incubation if the reaction lacked ATP, ubiquitin, E1, E2 or YopM (Figure 1b). To better understand the ubiquitin-ligase activity of YopM protein, we created a cDNA construct to express a YopM protein with C68A mutation. In contrast to wild-type (WT) YopM, C68A mutant failed to induce any autoubiquitination (Figure 1c), demonstrating that Cys 68 is 
a

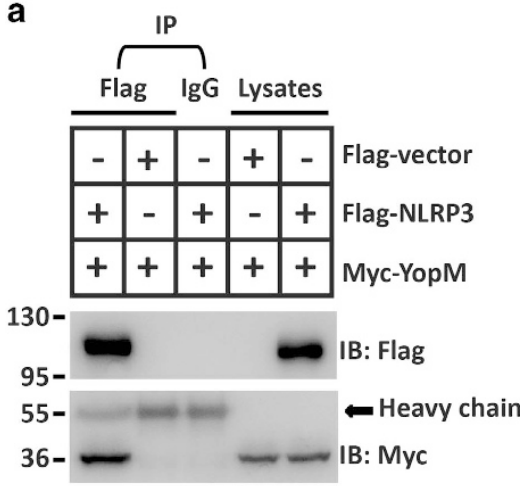

C

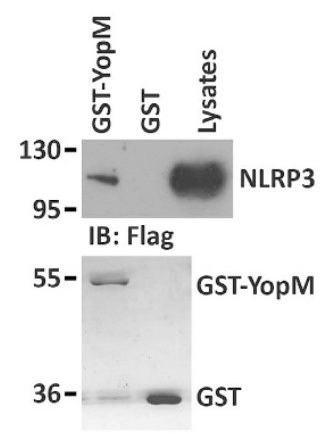

b
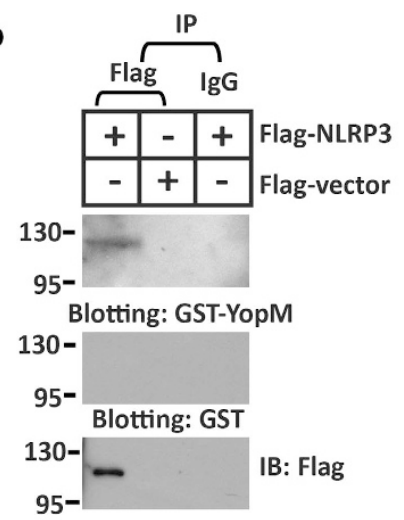

d

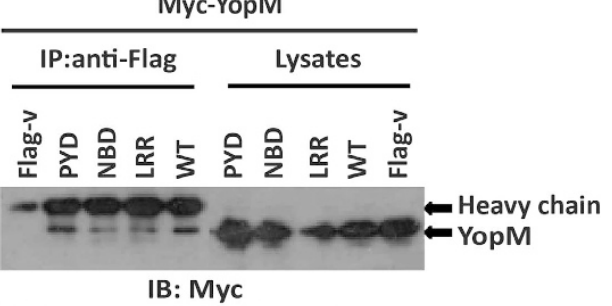

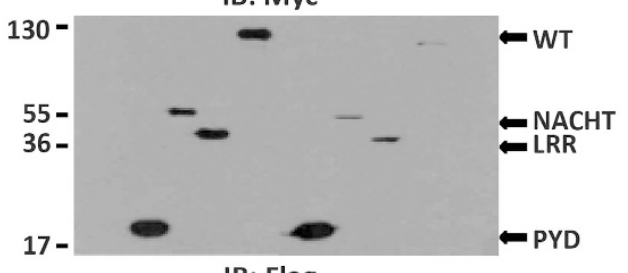

IB: Flag

Figure 2 YopM protein associates with NLRP3. (a) HEK293 cells were co-transfected with Flag-NLRP3 and Myc-YopM expression plasmids or Flag vector, and anti-Flag M2 Affinity Gel or lgG agarose immunoprecipitates were analyzed by immunoblotting with anti-Myc or anti-Flag antibody. (b) Anti-Flag or lgG immunoprecipitates prepared from cells transfected with Flag-NLRP3 or Flag vector-expressing plasmids were subjected to SDS-PAGE and blotted onto nitrocellulose membrane. The nitrocellulose membrane was incubated with soluble GST-YopM (upper) or GST (middle) for $2 \mathrm{~h}$ and then analyzed with anti-GST or anti-Flag antibody. (c) GST-tagged YopM were subjected to pull-down assay with the lysates of HEK293 cells transfected with Flag-NLRP3 expressing plasmid. Immunoblotting analyses with anti-Flag antibody was shown in the top. Loading of the GST proteins assessed by Coomassie blue staining was shown in the bottom. GST was used as a negative control. (d) HEK293 cells were co-transfected with the indicated vector encoding Myc-tagged YopM, Flag-tagged full-length NLRP3 or truncations of NLRP3 containing only residues 1-90 (pyrin domain) (PYD), 91-710 (nucleotide-binding domain) (NBD) or 711-1033 (LRR domain) (LRR), and anti-Flag immunoprecipitates were analyzed by immunoblotting with anti-Myc or anti-Flag antibody. All co-immunoprecipitation experiments were performed independently three times with comparable results. All cell-based experiments were performed independently three times with comparable results

the novel active site of YopM for the E3 ubiquitin ligase activity.

YopM protein associates with NLRP3. We then explored the possible host target of YopM. Yeast two-hybrid (Y2H) screening data revealed a possible interaction between YopM and NLRP3 (Supplementary Figure S1A). To confirm the yeast two-hybrid analysis, Flag-tagged NLRP3 and Myctagged YopM were transfected into HEK293 cells, and a coimmunoprecipitation experiment was performed. Myc-tagged YopM was detected in the anti-Flag immunoprecipitation from cells co-transfected with Flag-NLRP3, but not with a negative control Flag-tagged protein (Figure 2a). Vice versa, Flagtagged NLRP3 was detected in the anti-Myc immunoprecipitation from cells co-transfected with Myc-YopM, but not with a negative control Myc-tagged protein (Supplementary Figure S1B). To investigate the interaction between YopM variants of other Yersinia strains and NLRP3, Flag-tagged NLRP3 and Myc-tagged YopM (KIM5) were transfected into
HEK293 cells, and a co-immunoprecipitation experiment was performed. Myc-tagged YopM (KIM5) was also detected in the anti-Flag immunoprecipitation from cells co-transfected with Flag-NLRP3 (Supplementary Figure S1C). To demonstrate the interaction of YopM and NLRP3 in vitro, lysates from HEK293 cells expressing Flag-NLRP3 were incubated with glutathione S-transferase (GST) or GST-YopM fusion protein. Analysis of the absorbates by immunoblotting with anti-GST showed that NLRP3 bound GST-YopM, but not GST (Figure 2b). GST pull-down assay also showed an in vitro interaction between YopM and NLRP3 (Figure 2c). NLPR3 consists of an N-terminal pyrin domain (PYD), a central nucleotide binding or oligomerization domain (NBD, NOD, or $\mathrm{NACHT}$ ) and C-terminal LRRs. We then further analyzed the ability of the three domains of NLRP3 to associate with YopM. To this end, all three domains were involved in the interaction with YopM (Figure 2d). Since NLRP3 interacted with YopM, we suggested that NLRP3 might be a potential substrate of YopM E3 ubiquitin ligase. 
YopM mediates K63-linked ubiquitination of NLRP3. To explore whether NLRP3 is a substrate of YopM E3 ubiquitin ligase, we performed the in vitro ubiquitination assay using
Flag-NLRP3 as the substrate. Although we did not find CED motif in the C-terminal tail of YopM, we still mutated the only Cys 271 present in the LRR region and used YopM C271A as a
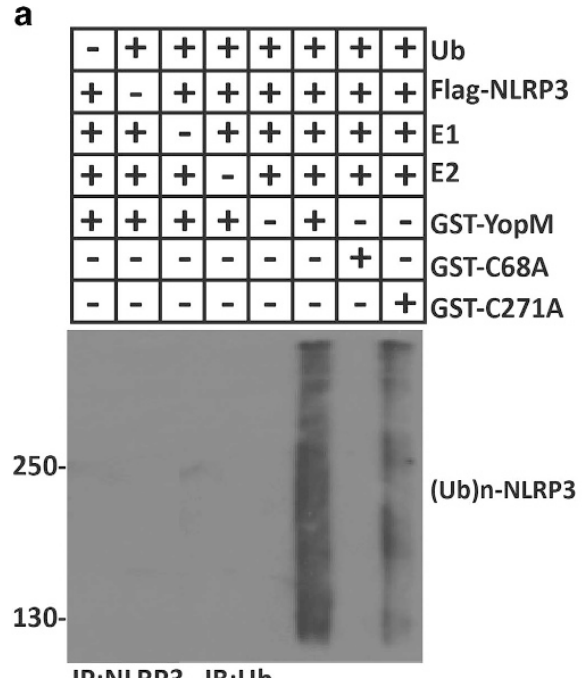

(Ub)n-NLRP3

IP:NLRP3 IB:Ub

55-

Input: WB

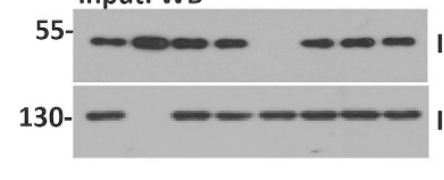

C
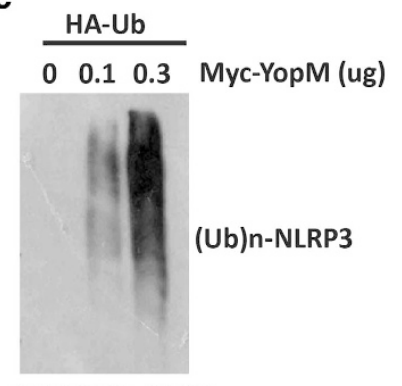

IP:NLRP3 IB:HA

Input: WB

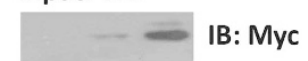

f

Hrs post $\Delta$ YopM infection

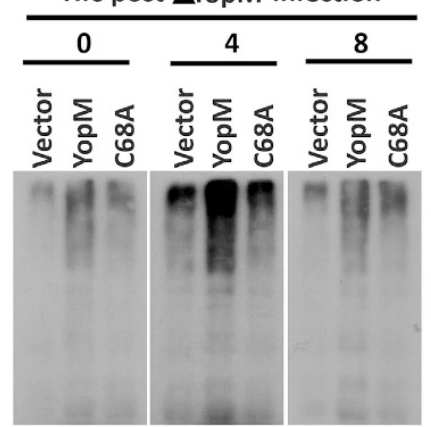

IP:NLRP3 IB:Ub

Input: WB

IB: GST

IB: Flag

e

(Ub)n-NLRP3 b

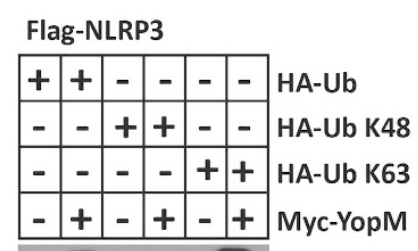

$250-$

$130-$

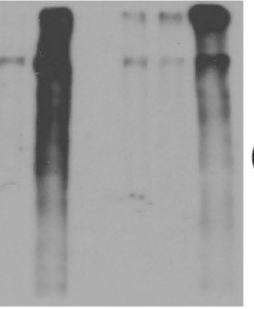

IP:Flag IB:HA Input: WB
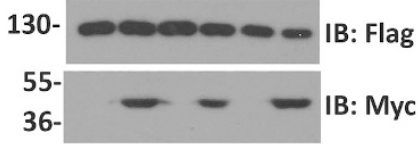

d

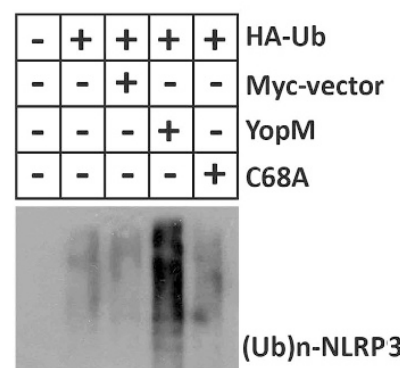

(Ub)n-NLRP3

Flag-NLRP3+HA-Ub K63

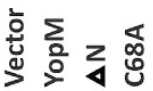

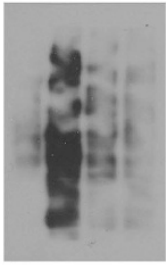

K63-(Ub)n-NLRP3

IP:Flag IB:HA

Input: WB

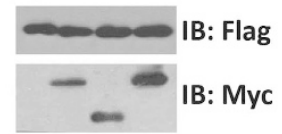

g
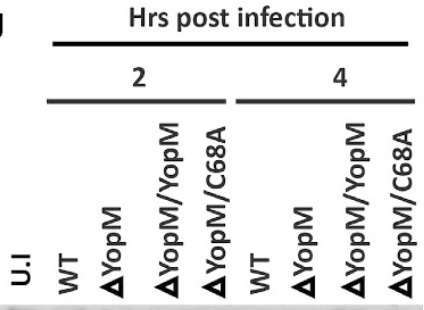

IP:NLRP3 IB:Ub

Input: WB
(Ub)n-NLRP3

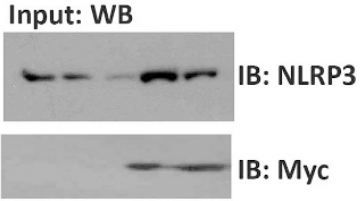


a control. Both WT YopM and YopM C271A mutant dramatically enhanced the ubiquitination of NLRP3 in the presence of E1 and E2 (Figure 3a), while YopM C68A mutant failed to increase the ubiquitination level of NLRP3, indicating the importance of Cys 68 active site in regulating NLRP3 functions. Furthermore, immunoprecipitation assay showed that YopM catalyzed the ubiquitination of NLRP3 mainly with ubiquitin containing a lysine residue only at position 63 (all others substituted with arginine), but at very low level with ubiquitin containing a lysine residue only at position 48 (Figure $3 b$ ). Congruence results showed that overexpression of YopM led to a considerable increase of endogenous NLRP3 ubiquitination (Figure 3c). In contrast to WT YopM, C68A mutant or $\Delta \mathrm{N}$ mutant failed to induce any endogenous NLRP3 polyubiquitination (Figures $3 d$ and e). In consistence, the ubiquitination of NLRP3 stimulated by $\triangle$ YopM bacterial infection was greatly reduced in the cells expressing YopM C68A than YopM WT (Figure 3f). Similarly, BMDMs infected with WT and $\triangle$ YopM/YopM $Y$. pesitis, but not $\triangle$ YopM or $\triangle$ YopM/C68A, showed increased NLRP3 ubiquitination (Figure $3 \mathrm{~g}$ ). Taken together, these results suggest that the CLD motif (68-70 aa) of YopM is responsible for the E3 catalytic activity of YopM on NLRP3.

YopM mediates the stabilization of NLRP3. We next sought to determine the effect of YopM on NLRP3 expression. When HEK293 cells were transfected with increasing amounts of plasmid encoding YopM, we found that the concentration of endogenous NLRP3 protein increased considerably with increasing YopM expression (Figure 4a). However, the YopM E3 ligase activity was required, since YopM C68A mutant lacking E3 ligase activity had compromised activity on NLRP3 stabilization. In contrast to WT YopM, YopM $\Delta \mathrm{N}$ mutant failed to induce any endogenous NLRP3 stabilization (Figure 4b). Quantitative RT-PCR revealed that YopM overexpression did not change NLRP3 mRNA levels (Figure 4c), suggesting that YopM upregulates NLRP3 protein expression by post-transcriptional mechanism. To determine the specificity of the YopM-mediated stabilization of NLRP3, we did similar experiments with cells expressing TBK1, ASC, pro-caspase-1, NLRP4, or NLRP5 with increasing YopM expression and found that YopM did not affect the concentration of all the other molecules tested (Supplementary Figure S2A). Indeed, the estimated half-life of NLRP3 in the presence of YopM was significantly longer than that in the presence of YopM C68A or YopM $\Delta \mathrm{N}$ mutant (Figure 4d). We then assessed whether YopM is able to mediate the stabilization of endogenous NLRP3 under physiological conditions by analysis of NLRP3 protein kinetics in response to bacterial infection, and observed that NLRP3 protein levels increased in WT $Y$. pestis-infected BMDMs within $3 \mathrm{~h}$ post infection. However, bacteria lacking YopM failed to induce any NLRP3 stabilization (Figure 4e). Moreover, Y. pestis infection-induced NLRP3 stabilization also required YopM E3 ligase activity (Figure 4e). These results indicate that NLRP3 is upregulated under physiological conditions of $Y$. pestis infection in a YopM-dependent manner.

YopM induces NLRP3-dependent necrosis in vitro. A role for NLRP3 in caspase-1 activation is well studied. Recent works have implicated another role of NLRP3 in triggering macrophages necrosis, which is independent of caspase-1 and IL-1 $\beta .^{39}$ We then try to determine whether YopM plays a role in NLRP3-mediated necrosis. We found that infection of WT Y. pestis dramatically decreased cell viability in BMDMs, while bacteria lacking YopM $(\triangle \mathrm{YopM})$ induced significantly less cell death as measured by lactate dehydrogenase (LDH) release. In addition, YopM-deficient bacteria complemented with YopM C68A induced significantly reduced cell death than those complemented with WT YopM (Figure 5a). Consistent with these findings, ectopic WT YopM expression, but not YopM C68A, led to significant cell death as compared with the vector-transfected control cells (Figure $5 b$ ). To further discriminate apoptotic and necrotic cell death induced by $Y$. pestis infection, FACS with Annexin $\mathrm{V}$ and PI double staining was performed. $\mathrm{H}_{2} \mathrm{O}_{2}$ was used a positive control to induce cell necrosis death. As was shown in Supplementary Figure S3A, a marked increase of necrosis was detected in WT and $\triangle$ YopM/YopM-infected BMDMs compared with that of $\triangle$ YopM or $\triangle$ YopM/C68A.

HMGB1 release is another distinctive marker to differentiate between necrosis and pyroptosis. Y. pestis infection or YopM transfection triggered significant HMGB1 release (Figure 5c and Supplementary Figure S3B), while knocking down of NLRP3 blocked YopM-induced cell death and decreased HMGB1 release (Figures $5 \mathrm{~b}$ and $\mathrm{c}$ ), indicating that YopMinduced necrosis is NLRP3-dependent. Previous reports indicated that NLRP3-mediated HMGB1 release is dependent on cathepsin $B,{ }^{40}$ we next sought to determine the effect of caspase-1-specific inhibitor YVAD-CHO, cathepsin B-specific inhibitor Ca-074-Me, and RIP1-specific inhibitor necrostatin-1 on YopM-induced cell necrosis. Pretreatment of cells with YVAD-CHO or necrostatin-1 failed to abrogate necrosis and HMGB1 release induced by YopM overexpression (Figure 5b and Supplementary Figure S3B) or $Y$. pestis infection (Figure $5 d$ and Supplementary Figure S3C). However, Ca-074-Me significantly attenuated $\mathrm{LDH}$ release and

Figure 3 YopM mediates K63-linked ubiquitination of NLRP3. (a) In vitro ubiquitylation assay with Flag-NLRP3 and a mixture of E1, E2s, ATP, ubiquitin, GST-YopM, or GSTYopM C68A. GST-YopM and Flag-NLRP3 were used to show equal loading. (b) Immunoblotting showing ubiquitination levels of NLRP3 in HEK293 cells transfected with FlagNLRP3, Myc-YopM, and HA-tagged ubiquitin, HA-tagged K48 ubiquitin (Ub K48) or HA-tagged K63 ubiquitin (Ub K63), treated with MG132 (10 $\mu$ M) for 12 h. (c) Immunoblotting showing ubiquitination levels of endogenous NLRP3 in HEK293 cells transfected with HA-tagged ubiquitin together with different doses of Myc-YopM. (d) Immunoblotting showing ubiquitination levels of endogenous NLRP3 in BMDMs transfected with HA-tagged ubiquitin together with Myc-YopM or Myc-YopM C68A. (e) Immunoblotting showing ubiquitination level of NLRP3 in HEK293 cells transfected with Flag-NLRP3, HA-tagged K63 ubiquitin together with Myc-YopM, Myc-YopM C68A, or Myc-YopM $\triangle$ N. (f) BMDMs cells transfected with Flag-YopM or Flag-YopM C68A were infected Y. pestis $\triangle$ YopM $(\mathrm{MOI}=20)$. Cell extracts were prepared at the indicated time points and anti-NLRP3 immunoprecipitates were analyzed by immunoblotting with anti-Ub antibody. (g) BMDMs were infected with different background of $Y$. pestis. After infection, cell extracts were prepared at the indicated time points and anti-NLRP3 immunoprecipitates were analyzed by immunoblotting with anti-Ub antibody. Cell-based studies were performed independently three times with comparable results 
HMGB1 release in both models, indicating the involvement of cathepsin $\mathrm{B}$ in this biological process.

Interestingly, $\triangle$ YopM infection in BMDMs failed to upregulate NLRP3 and HMGB1 secretion, but significantly induced caspase-1 activation and IL-1 $\beta$ secretion. On the contrary, $\triangle$ YopM/YopM rescue strain infection triggered increased HMGB1 release without inducing caspase-1 cleavage and $\mathrm{IL}-1 \beta$ secretion (Figures $5 \mathrm{e}$ and $\mathrm{f}$ ). We thus concluded that a

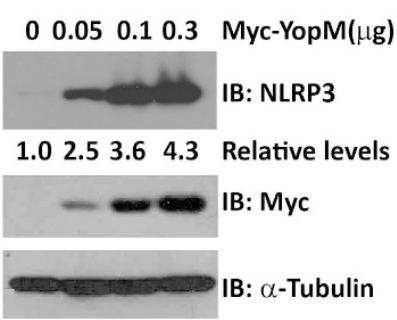

b

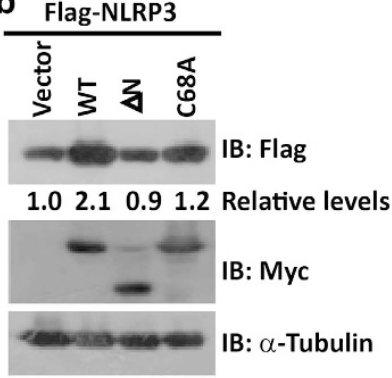

C

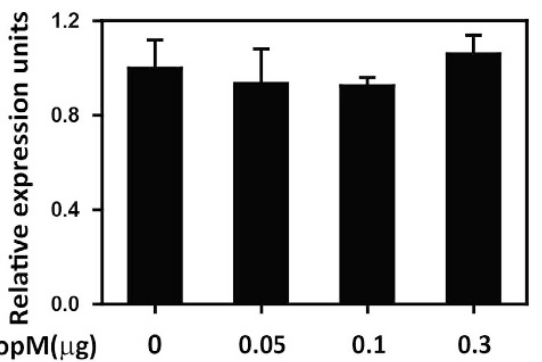

d

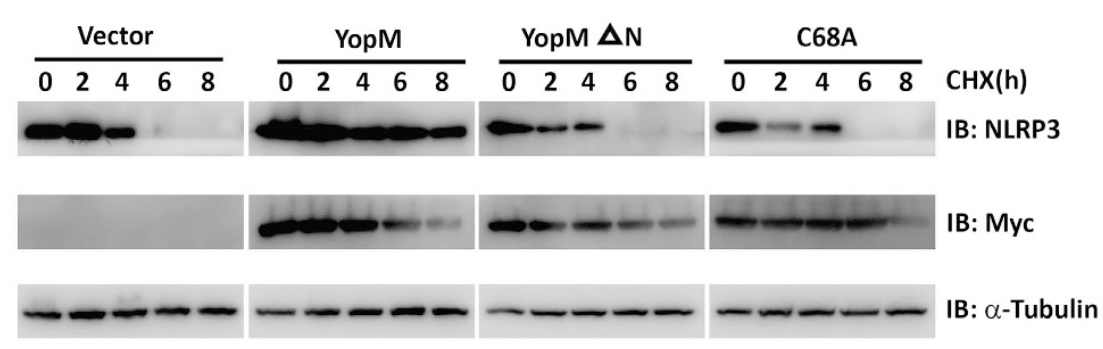

e

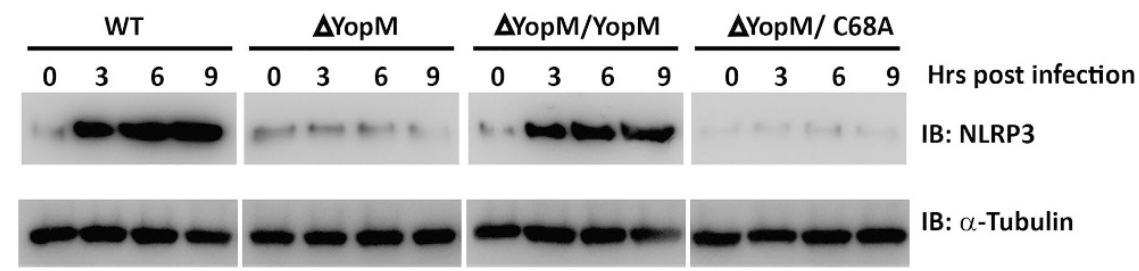

Figure 4 YopM mediates the stabilization of NLRP3. (a) Immunoblotting analysis of extracts of HEK293 cells transfected with increasing doses of plasmid for YopM using antiNLRP3 antibody. $\alpha$-Tubulin was used as equal loading control. (b) Immunoblotting analysis of extracts of HEK293 cells transfected with plasmid for Flag-NLRP3 together with Myc-YopM, Myc-YopM $\Delta \mathrm{N}$, or Myc-YopM C68A showing NLRP3 stability. $\alpha$-Tubulin was used as equal loading control. (c) Quantitative RT-PCR analysis of NLRP3 mRNA levels in HEK293 cells transfected with increasing doses of plasmid for YopM. (d) HEK293 cells were transfected with the expression vector encoding Flag-NLRP3, Myc-YopM, Myc-YopM C68A or Myc-YopM $\Delta \mathrm{N}$. After $24 \mathrm{~h}$, cells were treated with cycloheximide $(10 \mu \mathrm{M})$ at the indicated time points, and the level of NLRP3 was monitored by immunoblotting using anti-Flag antibody. $\alpha$-Tubulin was used as equal loading control. (e) BMDMs were infected with different background of $Y$. pestis. After infection, cell extracts were prepared at the indicated time points and subjected to immunoblotting. Cell-based studies were performed independently two to three times with comparable results

Figure 5 The importance of YopM E3 ligase activity in NLRP3-mediated necrotic cell death. (a) BMDMs were infected, respectively, with Y. pestis WT, $\Delta$ YopM, $\Delta$ YopM/YopM or $\Delta$ YopM/YopM C68A mutant bacteria for the indicated time $(\mathrm{MOI}=20)$. After $Y$. pestis invasion, supernatants from macrophages were collected at the time points indicated, and percent LDH was determined. (b) BMDMs cells were treated with or without $100 \mu \mathrm{M}$ caspase-1-specific inhibitor YVAD-CHO, $50 \mu \mathrm{M}$ Cathepsin B-specific inhibitor Ca-074-Me or $30 \mu \mathrm{M}$ RIP1-specific inhibitor necrostatin-1 and then transfected with expression plasmids encoding for Flag-YopM or its mutants or NRLP3 siRNA oligos (siNRLP3). Supernatants were collected at $24 \mathrm{~h}$ after transfection and analyzed for LDH release. (c) BMDMs cells were transfected with scrambled or NLRP3 siRNA oligos (si NLRP3) and then infected with $Y$. pestis. Cell extracts and supernatants were prepared at indicated time points. The whole-cell lysates were analyzed by immunoblotting with anti-NLRP3, anticaspase-1 Abs. The supernatants were analyzed by immunoblotting with anti-HMGB1. $\alpha$-Tubulin was used as equal loading control. (d) BMDMs cells were treated with or without $100 \mu \mathrm{M}$ caspase-1-specific inhibitor YVAD-CHO, $50 \mu \mathrm{M}$ Cathepsin B-specific inhibitor Ca-074-Me or $30 \mu \mathrm{M}$ RIP1-specific inhibitor necrostatin-1 before infection. BMDMs were infected with $Y$. pestis, cell extracts and supernatants were prepared at $24 \mathrm{~h}$. The whole-cell lysates were analyzed by immunoblotting with anti-NLRP3, anti-caspase-1 Abs. The supernatants were analyzed by immunoblotting with anti-HMGB1. $\alpha$-Tubulin was used as equal loading control. (e and f) BMDMs were infected, respectively, with $Y$. pestis WT, $\Delta$ YopM, $\Delta$ YopM/YopM, or $\Delta$ YopM/YopM C68A mutant bacteria for the indicated time $(\mathrm{MOI}=20)$. After $Y$. pestis invasion, cell extracts and supernatants were prepared at indicated time points. The whole-cell lysates were analyzed by immunoblotting with anti-NLRP3, anti-ASC, and anti-caspase-1 Abs. The supernatants were analyzed by immunoblotting with anti-HMGB1 Abs (e) or analyzed by ELISA for IL-1 $\beta$ (f). $\alpha$-Tubulin was used as equal loading control. (g) BMDMs cells were transfected with the expression vector encoding Myc-YopM, Myc-YopM C68A. After $24 \mathrm{~h}$, cells were primed for $4 \mathrm{~h}$ with $1 \mathrm{ng} / \mathrm{ml}$ LPS and stimulated with ATP (2.5 mM) for $30 \mathrm{~min}$ or CTB (20 mg/ml) for $16 \mathrm{~h}$. The whole-cell lysates were analyzed by immunoblotting with anti-Myc and anti-caspase-1 Abs. $\alpha$-Tubulin was used as equal loading control. (h) Recombinant caspase-1 was preincubated with GST-YopM or GST-YopM(C68A) for 5 min at $37^{\circ} \mathrm{C}$ in assay buffer. Caspase-1 substrate Ac-YVAD-pNA was added, and cleavage was detected by monitoring of absorbance at $405 \mathrm{~nm}$. Cell-based studies were performed at least three times independently with comparable results. Data were presented as mean \pm S.E.M. Student's $t$-test was used for statistical analysis: ${ }^{* *} P<0.01$ 
YopM induced cell necrosis in NLRP3-dependent but caspase-1 and IL-1 $\beta$ independent manner.

YopM has been reported previously to block caspase-1 activity. We then investigate the possible impact of the YopM

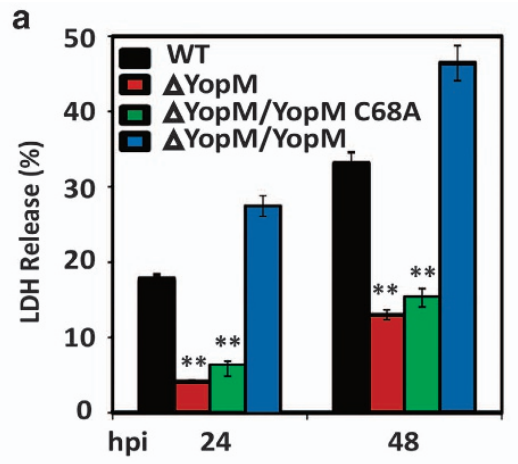

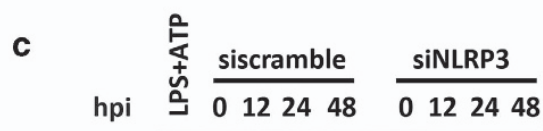

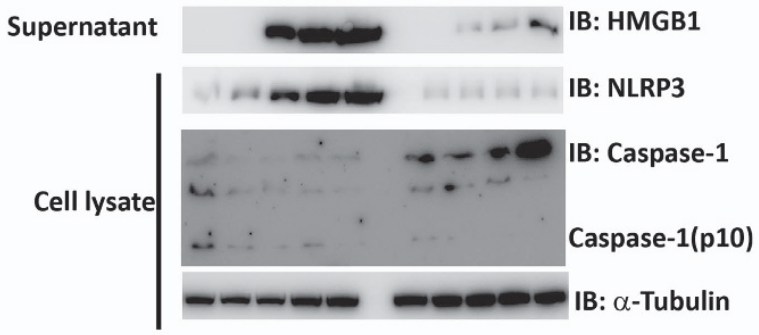

e $\frac{\text { WT }}{01224} \frac{\Delta \text { YopM }}{01224} \frac{\Delta \text { YopM/YopM }}{01224} \frac{\Delta \text { YopM/ }}{01224}$ c68A

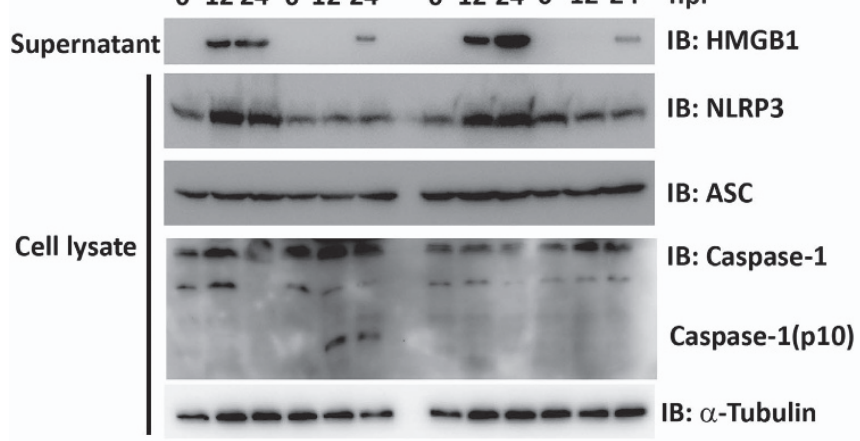

g

Myc-vector Myc-YopMMyc-C68A
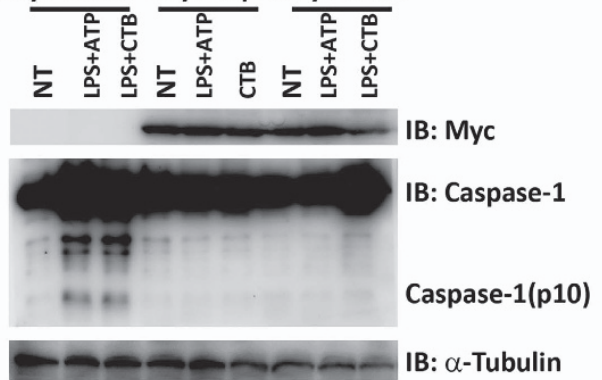

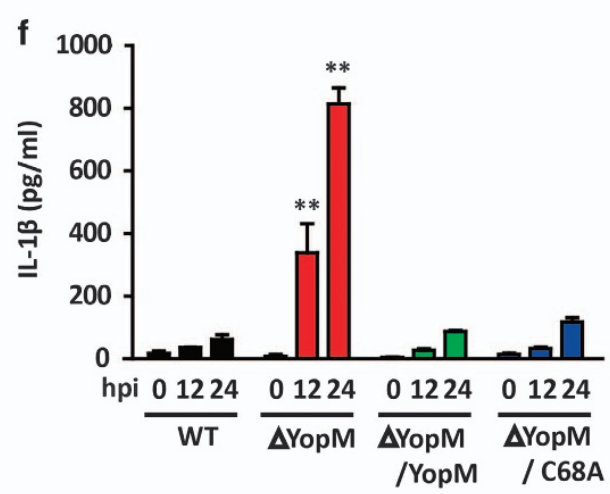

C68A mutant on inflammasome activation. We first transfected WT YopM or its C68A mutant into BMDMs and use LPS + ATP or LPS+CTB as canonical/noncanonical NLRP3 inflammasome agonist. Both WT YopM and C68A overexpression

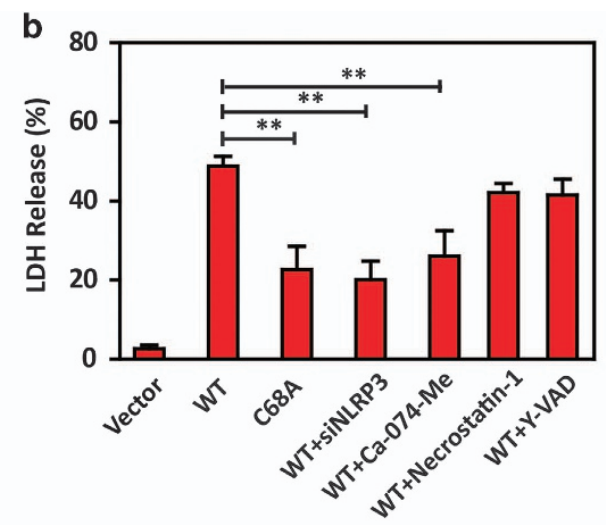

d
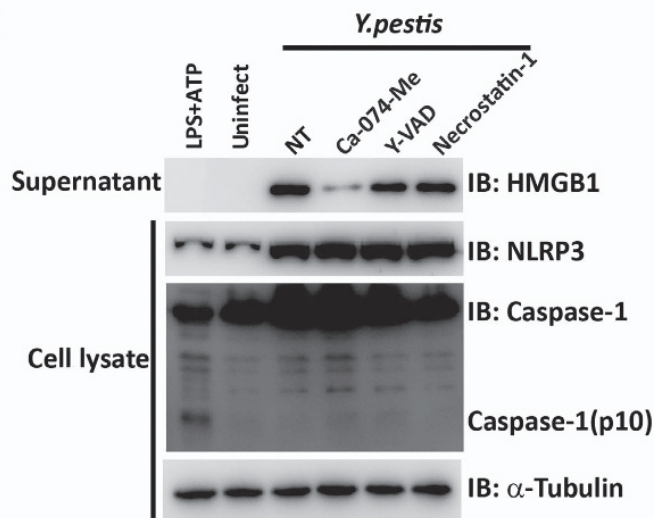

h

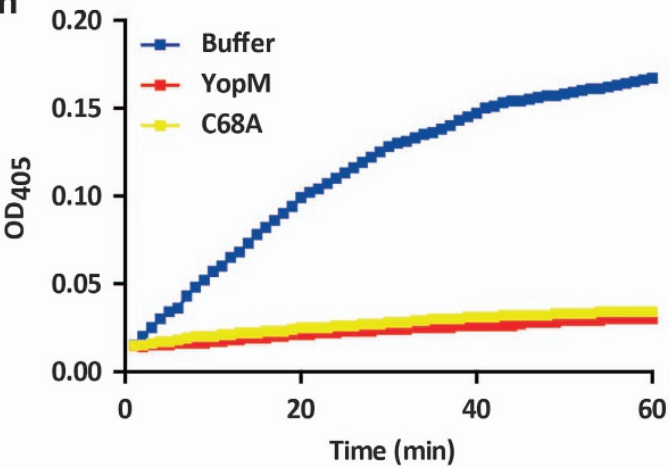


inhibited caspase-1 activation (Figure $5 \mathrm{~g}$ ). In consistence, both $\Delta$ YopM/YopM and $\Delta$ YopM/C68A infection failed to activate caspase-1 cleavage (Figure 5e). Furthermore, caspase-1 activity analysis by colorimetric assay showed that both YopM and its C68A mutant could inhibit caspase-1 activity (Figure 5h). Taken together, these results indicated that the ability of YopM to block the formation of the mature inflammasome and inhibit caspase-1 activation does not require its E3 ligase activity.

YopM induces necrotic cell death in vivo. To further delineate the role of YopM in necrotic cell death in vivo, we analyzed serum HMGB1 levels from mice infected with YopM and its mutants. As was shown in Figure 6a, WT and $\Delta$ YopM/ YopM-infected mice displayed significantly increased serum HMGB1 levels as compared with the $\triangle Y$ YopM and $\triangle$ YopM/YopM C68A-infected mice with the infection time progressed (Figure 6a), while serum IL-1 $\beta$ levels were not markedly elevated in WT, $\triangle$ YopM/YopM, and $\triangle$ YopM/YopM C68Ainfected mice (Figure 6b). Furthermore, significantly increased staining of NLRP3 in the inflammatory lesions of the lung, liver, and spleen (where bacteria are found) from the WT and $\triangle$ YopM/YopM infected mice as compared with $\triangle$ YopM and $\triangle$ YopM/YopM C68A was identified (Figures $6 \mathrm{~b}$ and $\mathrm{c}$ ). Therefore, YopM E3 ligase activity contributes to NLRP3-mediated HMGB1 release and necrosis in vivo.

YopM E3 ligase activity contributes to bacterial virulence. HMGB1 releasing elicits a severe inflammatory response, leading to tissue injury, and lethal sepsis in several infectious diseases. The exacerbated HMGB1 release and cell necrosis induced by YopM E3 ligase activity indicates its potential role in pesitis virulence. After challenging mice by intravenous injection of WT, $\triangle$ YopM, $\Delta$ YopM/YopM, or $\Delta$ YopM/YopM C68A Y. pestis, Mice were more resistant to $\Delta$ YopM or $\Delta$ YopM/YopM $\mathrm{C} 68 \mathrm{~A}$ infection in overall survival assays (Figure $7 \mathrm{a}$ ).
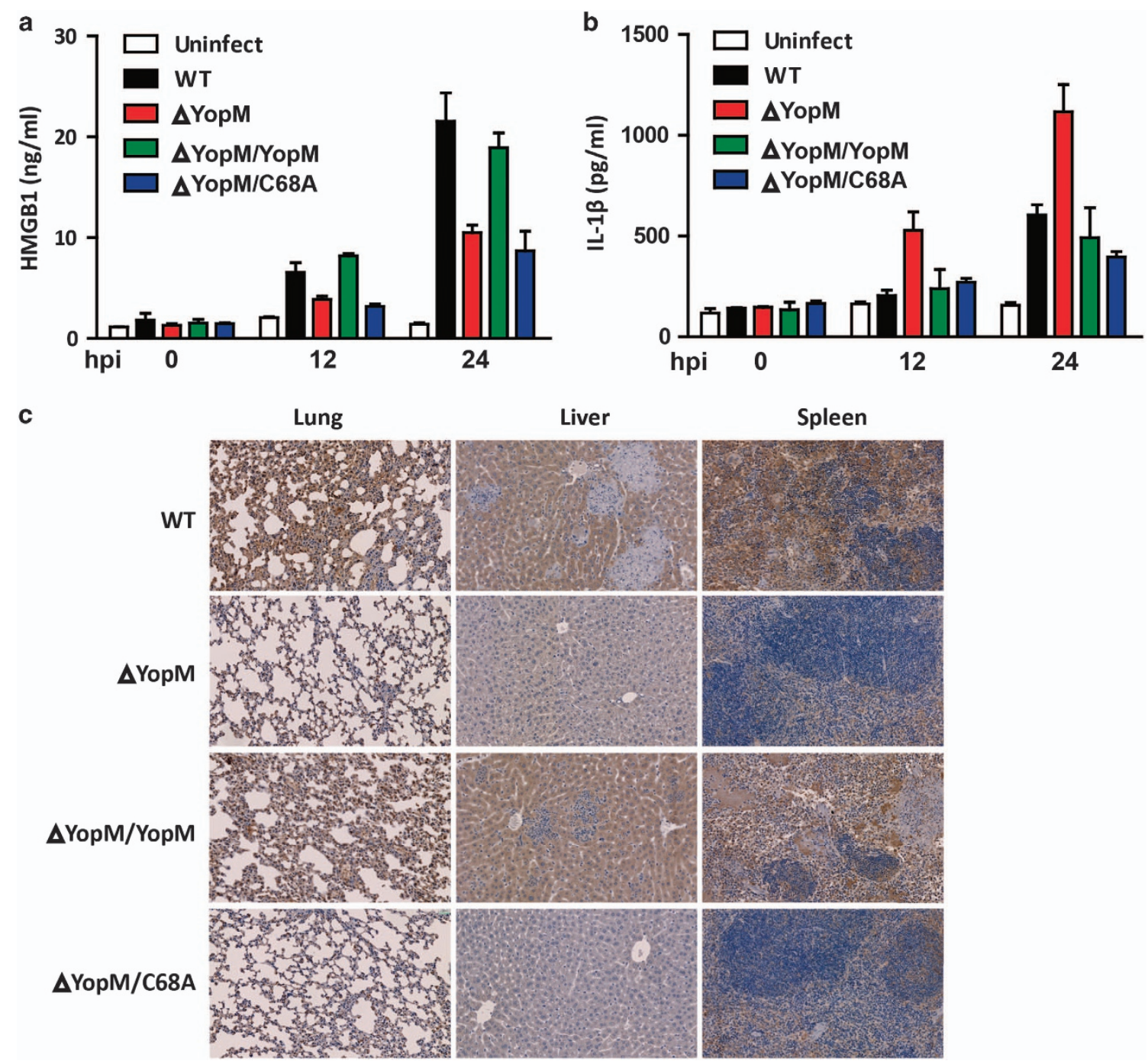

Figure 6 YopM E3 ligase activity contributes to NLRP3-mediated HMGB1 release and necrosis in vivo. (a-b) C57BL/6 mice were challenged by intravenous infection with 100 CFUWT, $\Delta$ YopM, $\Delta$ YopM/YopM, or $\Delta$ YopM/YopM C68A Y. pestis, serum were collected at $12 \mathrm{~h}$ and $24 \mathrm{~h}$ post infection and levels of HMGB1 (a) and IL-1 $\beta$ (b) were determined by ELISA. (c) Lung, liver, or spleen from mice infected with WT, $\Delta$ YopM, $\Delta$ YopM/YopM, or $\Delta$ YopM/YopM C68A strains for 3 days were subjected to immunohistochemical staining of NLRP3. All images are representative and were taken at $\times 40$ magnification. Data shown are representative from two independent experiments ( $n=5$ mice per strain) 

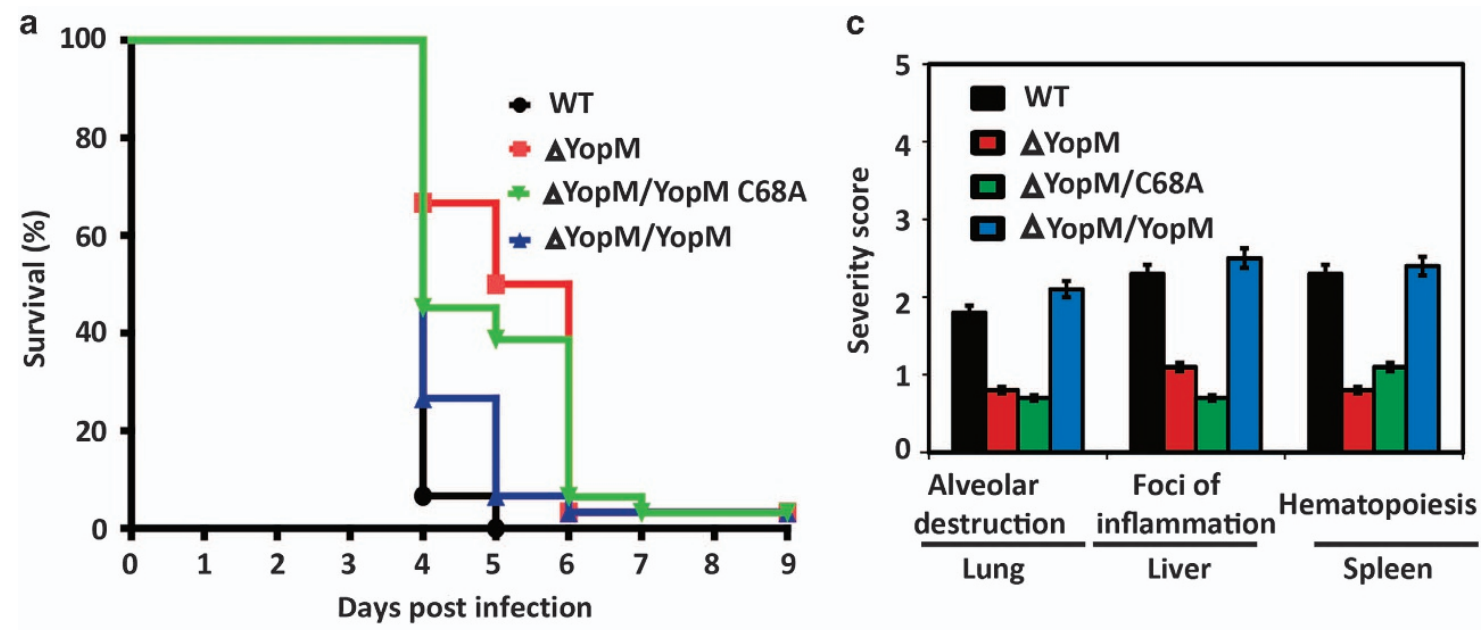

b

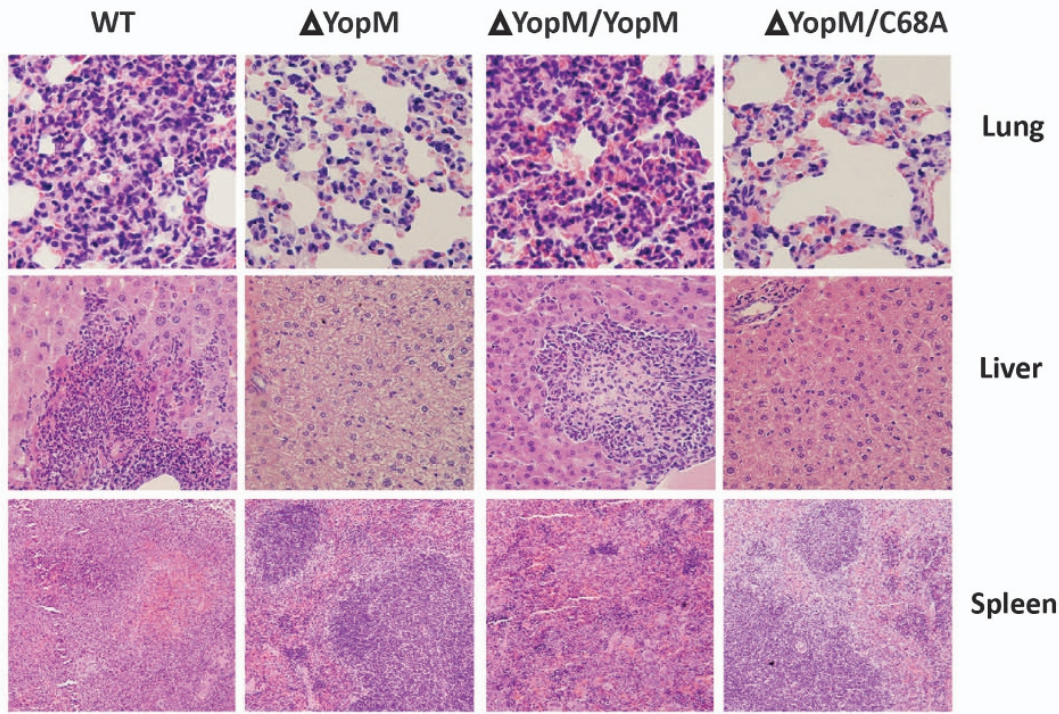

Figure 7 YopM E3 ligase activity is important for bacterial virulence. (a) Groups of 15 male and female mice were challenged by intravenous injection of 100 CFU WT, $\Delta$ YopM, $\Delta$ YopM/YopM, or $\Delta$ YopM/YopM C68A Y. pestis and monitored over 10 days for development of disease. Data shown were collected in two independent experiments, $n=15$ mice per group in each experiment. (b) Lung, liver, or spleen from mice infected with WT, $\Delta$ YopM, $\Delta$ YopM/YopM, or $\Delta$ YopM/YopM C68A strains for 3 days were subjected to histopathological analysis by staining with HE. Each micrograph shows an example of the pathology caused by each strain. Data shown are representative from two independent experiments ( $n=5$ mice per strain). (c) Mean severity scores for histopathology of lungs, liver, and spleen from mice infected with different background of bacteria strains on day 3

We then examined disease pathology by staining formalin fixed lungs, liver, and spleen with HE staining (Figure 7b). Total pathological severity scoring of lungs, liver, and spleen indicated a significantly increased inflammation, tissue injure and necrosis in WT and $\triangle$ YopM/YopM bacteria infected tissues, while the $\triangle$ YopM or $\triangle$ YopM/YopM C68A strain generally caused low levels of inflammation and necrosis (Figure 7c). Therefore, we conclude that YopM E3 ligase activity is essential for virulence.

\section{Discussion}

During host-pathogen interactions, pathogens can release their PAMPs into the host cell cytosol by various means. ${ }^{41}$ NLRs and RIG-I-like receptors (RLRs) respond rapidly to PAMPs found within the host cell cytosol and trigger cell death. ${ }^{42,43}$ Here we show that cytosolic detection of Y. pestis- derived T3SS effectors is a major mechanism of inducing necrosis, and this process requires signaling mainly through NLRP3. In addition, the E3 ligase activity of YopM functions as an essential signaling adaptor, linking the cytosolic detection of bacteria to the NLRP3-mediated necrotic cell death signaling pathway. Here we report evidence that YopM itself, a conservative molecule in $Y$. pestis species, is a unique simulator of NLRP3. The activity of YopM lies in its CLD motif, a conserved CXD motif located in N-terminal domain, which is responsible and crucial for the E3 activity of YopM. Our biochemical analysis identified a host protein, NLRP3, as the target of YopM. Although a number of NLRs were identified, we did not observe any effect of YopM on NLRP4 or NLRP5. Our results thus revealed a microbial product that is responsible for NLRP3-mediated necrotic cell death, in addition to the well-known bacterial secretion systems and other bacterial contaminants. 
The expression of NLRP3 is tightly controlled to restrict its ability to directly recognize pathogens. ${ }^{44}$ Previous reports showed that the activation of inflammasome required both NLRP3 expression induction and NLRP3 inflammasome assembly. ${ }^{45}$ LPS is also known to induce NLRP3 mRNA and protein expression. This dual stimulation requirement may operate to prevent accidental or uncontrolled NLRP3 activation. However, the mechanisms governing NLRP3-induced necrosis have not been conclusively delineated. Here we found that YopM is a conservative $Y$. pestis product that can activate NLRP3 expression, YopM itself is sufficient for NLRP3-mediated necrosis as NLRP3 agonist by promoting its K63-linked ubiquitination, suggesting that cell necrosis may associated with K63-linked ubiquitination of NLRP3. Further characterization of the NLRP3 ubiquitination mechanism and the identification of the host NLRP3 ubiquitination enzymes would enhance our understanding of the mechanism of NLRP3 in necrosis signaling pathway.

Pathogens have been shown to use different strategies to modulate innate immune signaling pathway. ${ }^{46,47}$ For example, Kaposi's sarcoma-associated herpes virus (KSHV) encodes a protein called Orf3 to interact with NLRP1, NLRP3, and NOD2 and to repress $\mathrm{IL}-1 \beta$ production during $\mathrm{KSHV}$ infections. ${ }^{48}$ Salmonella is known to downregulate the expression of flagellin to avoid detection by the inflammasome. ${ }^{49}$ However, recent reports suggest that $S$. typhimurium activates caspase-1 directly through T3SS effector protein SopE. ${ }^{50}$ Shigella induced necrotic host cell death pathway requiring both NRLP3 and ASC, but caspase-1 independent. ${ }^{51} Y$. pestis KIM-infected macrophages released HMGB1, and microscopic analysis revealed that necrotic cells contained active caspase-1, indicating that caspase- 1 activation is associated with necrosis. ${ }^{26}$ Previous study indicated YopM is a pseudosubstrate inhibitor of caspase-1 activity, which as a potent antagonist of both caspase- 1 activity and activation. ${ }^{37}$ Moreover, recent study indicated IQGAP1 is important for activation of caspase-1 in macrophages; YopM can also inhibit caspase-1 activation independently of a pseudosubstrate motif through IQGAP1 dependent pathway. ${ }^{52}$ Our results support previous data indicating that $Y$. pestis induced NLRP3dependent yet caspase-1 independent necrosis, and contributes to bacterial virulence by inducing cell necrosis.

Pathogenic infection triggered the release of HMGB1, a proinflammatory factor released by necrotic cells. Once HMGB1 is released, several proinflammatory cytokines is induced and severe inflammatory response is elicited. ${ }^{51}$ Treatment with a neutralizing antibody of HMGB1 has been shown to significantly reduce inflammation and improve survival in animal models. ${ }^{53}$ We report that serum HMGB1 is increased during $Y$. pestis infection in mice. The release of HMGB1 elicited by $Y$. pestis-induced cell death further supports the use of HMGB1 antagonists to reduce mortality rate during $Y$. pestis infection.

Cathepsin B is a cysteine protease that is located in lysosomes and degrades in an acidic environment. ${ }^{54}$ Previous reports show that cathepsin $B$ has some role in the process of NRLP3-mediated necrosis before inflammasome formation. ${ }^{40}$ Our data suggests that cathepsin B inhibitor CA-074-Me abrogated YopM induced NLRP3-dependent HMGB1 releases, indicating that cathepsin $B$ is indispensable in this type of cell death.
Rapid bacterial replication in the absence of inflammation in the early phase transitions to a highly proinflammatory phase with increased inflammatory cytokine production and tissue damage. ${ }^{55}$ Host cell apoptosis decreases while pyroptosis or other forms of inflammatory cell death increase. ${ }^{56}$ Y. pestis initially replicate in the host without inducing inflammation by antagonize caspase-1-dependent pathway to enhance their virulence. An initial noninflammatory phase of $Y$. pestis replication is followed by inflammation. Here we proposed that YopM regulated necrotic cell death through NLRP3 in the later time during their infection. As opposed to the study by LaRock and Cookson showing that YopM deletion in $Y$. pseudotuberculosis YPIII (serogroup 0:3) results in 100\% survival, our host survival results suggested that YopM deficiency in $Y$. pestis was mainly associated with delayed mortality. YopM is composed of a variable number of 20 or 22 amino acid LRRs, which are known to mediate protein-protein interactions. ${ }^{27}$ Different Yersinia strains encode distinct YopM isoforms, with 15-LRR isoform in Y. pseudotuberculosis YPIII (serogroup 0:3) and 13-LRR isoform in Y. pestis (91001) strains. $^{52}$ The differences of YopM LRRs repeats between these two strains maybe the main cause of virulence difference. In addition, Y. pseudotuberculosis YPIII (serogroup 0:3) was naturally deficient in YopT. ${ }^{37}$ YopM deficiency in YopT defective background may lead to varied phenotypes between $Y$. pestis and Y. pseudotuberculosis YPIII (serogroup O:3). Further investigation on the impact of YopM on $Y$. pestis induced necrosis would greater our understanding on the underestimated proinflammatory functions of YopM on plague pathogenesis.

\section{Materials and Methods}

Strains, plasmids and reagents. Y. pestis strain 91001 was used as the wild -type bacteria. ${ }^{57}$ The construction of $Y$. pestis strain 91001 with mutant YopM was carried out as described previously. ${ }^{58-60}$ The pACYC184 vector was used to construct the YopM or YopM C68A (the 68th cysteine residue was replaced by alanine) overexpressing strains. The resultant plasmids were introduced into Y. pestis $\triangle$ YopM strain. The YopM or YopM C68A coding sequence was amplified by PCR and cloned into pcDNA3-Flag, pCMV-Myc, and PCMV-HA vectors, respectively. Vectors and epitope tagging of Flag-tagged NLRP3 and their mutants were expressed by cloning the genes into the pcDNA3-based vector (Invitrogen, San Diego, CA, USA). Glutathione S-transferase (GST) fusion proteins were generated by expression in pGEX4T-1-based vectors (Amersham Biosciences Biotech, Inc., Uppsala, Sweden) in Escherichia coli BL21 (DE3). All plasmids were verified by restriction enzyme analysis and DNA sequencing. Cathepsin $B$ inhibitor CA-074-Me was obtained from Sigma (C5857; Sigma, St Louis, MO, USA). YVADCHO was obtained from Enzo (ALX-260-027; Enzo, Farmingdale, NY, USA). Necrostatin-1 was obtained from Sigma (N9037).

Cell culture and infection conditions. Human embryonic kidney (HEK293) cells were grown in Dulbecco's modified Eagle's medium (DMEM. Invitrogen) supplemented with $10 \%$ heat-inactivated fetal bovine serum (FBS, HyClone, Logan, UT, USA), $2 \mathrm{mM} \mathrm{L-glutamine,} 100 \mathrm{U} / \mathrm{ml}$ penicillin, and $100 \mathrm{mg} / \mathrm{ml}$ streptomycin. Transient transfections were performed with jetPRIME in vitro DNA and siRNA transfection reagent (Polyplus, NY, USA) following manufacturer's instructions. WT Yersinia were grown overnight with aeration in medium broth at 28$30^{\circ} \mathrm{C}$, and $\Delta$ YopM/YopM Yersinia were grown with $10 \mu \mathrm{g} / \mathrm{ml}$ kanamycin and amino benzyl penicillin. The $\Delta$ YopM/YopM and $\Delta$ YopM/YopM C68A RPMl1640 medium (without streptomycin and penicillin) was added with $20 \mu \mathrm{g} / \mathrm{ml}$ Chloramphenicol $1 \mathrm{~h}$ before the infection. Bacteria were added to the cells at the indicated $\mathrm{MOI}$ and spun onto the cells at 1500 r.p.m. for $5 \mathrm{~min}$. Cells were incubated at $37^{\circ} \mathrm{C}$ for $0.5 \mathrm{~h}$ post infection followed by addition of $10 \mu \mathrm{g} / \mathrm{ml}$ gentamicin.

Bone marrow-derived macrophage (BMDM) isolation. Bone marrow cells from femur exudates of C57BL/6 were grown at $37^{\circ} \mathrm{C}$ in a humidified incubator 
in RPMl 1640 medium (RPMl, Invitrogen) containing 10\% FBS, 2 mM L-glutamine, $100 \mathrm{U} / \mathrm{ml}$ penicillin, $100 \mathrm{mg} / \mathrm{ml}$ streptomycin and $100 \mathrm{ng} / \mathrm{ml}$ mouse GM-CSF (Peprotech, Rocky Hill, NJ, USA) for 7 days. Differentiated BMDMs were replated into six-well dishes $18 \mathrm{~h}$ before infection.

In vivo ubiquitination assay. HEK293 cells were co-transfected with plasmids expressing Flag-NLRP3, Myc-YopM, HA-tagged ubiquitin or HA-tagged K48-only ubiquitin or HA-tagged K63-only ubiquitin. Cells were immunoprecipitated with anti-Flag antibody. The polyubiquitination signal was detected using anti-HA of anti-NLRP3 antibodies.

For detection of endogenous ubiquitinated-NLRP3 following $Y$. pestis infection, cells were infected at $\mathrm{MOI}=20$ and harvested for whole-cell extracts at the indicated times. Immunoprecipitation was performed on $1 \mu \mathrm{g}$ of protein with anti-NLRP3 antibody. After transfer, the membrane was denatured in $6 \mathrm{M}$ guanidine- $\mathrm{HCl}$ solution $(6 \mathrm{M}$ guanidine- $\mathrm{HCl}$, $20 \mathrm{mM}$ Tris- $\mathrm{HCl}, \mathrm{pH}$ 7.5, $1 \mathrm{mM}$ phenylmethylsulfonyl fluoride, and $5 \mathrm{mM}$ dithiothreitol) for $30 \mathrm{~min}$ at room temperature. The polyubiquitination signal was detected using an antiubiquitin monoclonal antibody (sc-166553, Santa Cruz Biotechnology, Dallas, TX, USA).

In vitro ubiquitylation assay. In vitro ubiquitination assays (Enzo Ubiquitinylation Kit) were performed in $50 \mu \mathrm{l}$ reaction mixture containing reaction buffer $\left(25 \mathrm{mM}\right.$ Tris- $\mathrm{HCl}$ at pH 7.5, $50 \mathrm{mM} \mathrm{NaCl}, 5 \mathrm{mM} \mathrm{ATP}, 10 \mathrm{mM} \mathrm{MgCl}_{2}$ and $0.1 \mathrm{mM}$ DTT), $2.5 \mu \mathrm{l} 1,5 \mu \mathrm{l}$ mixed E2, and $2.5 \mu \mathrm{l}$ ubiquitin purified in the presence or absence of GST-YopM or GST-YopM C68A at the indicated times. For in vitro NLRP3 ubiquitylation by YopM, reactions were performed as for autoubiquitination assays except that $1 \mu \mathrm{g}$ purified Flag-NLRP3 was included. The reactions were incubated at $37^{\circ} \mathrm{C}$ for $1 \mathrm{~h}$ and stopped by the addition of $5 \times$ Laemmli sample buffer. ${ }^{61}$

Immunoblotting and Co-immunoprecipitation. Cell lysates were prepared in lysis buffer $(50 \mathrm{mM}$ Tris- $\mathrm{HCl}(\mathrm{pH} 7.5), 1 \mathrm{mM}$ phenylmethylsulfonyl fluoride, $1 \mathrm{mM}$ dithiothreitol, $10 \mathrm{mM}$ sodium fluoride, $10 \mathrm{mg} / \mathrm{ml}$ aprotinin, $10 \mathrm{mg} / \mathrm{ml}$ leupeptin, $150 \mathrm{mM} \mathrm{NaCl}$, and $10 \mathrm{mg} / \mathrm{ml}$ pepstatin A) containing 1\% NP-40. Soluble proteins were subjected to immunoprecipitation with anti-Flag or Anti-Myc Agarose Affinity Gel (Sigma-Aldrich) antibodies. An aliquot of the total lysates (5\%, v/v) was included as control. Immunoblotting analysis was performed with anti-Myc, anti-HA, anti-Flag, anti- $\alpha$-Tubulin (Sigma-Aldrich), anti-HMGB1 (ab92310, Abcam, Cambridge, UK), anti-caspase-1 (sc-514, Santa Cruz Biotechnology), anti-ASC (sc-271054, Santa Cruz), and anti-NLRP3 (AG-20B-0014-C100, Adipogen, San Diego, CA, USA) antibodies, respectively. The antigen-antibody complexes were visualized by chemiluminescence (5200, Tanon, Inc., Shanghai, China). The Band Analysis tools of Gel Image System software version 4.2 (Tanon) were used to select and determine the background-subtracted density of the bands in all the gels and blots. Level of protein was first normalized to respective tubulin control. The control (wild-type) condition was normalized to 1 and all other experimental conditions were compared with this.

ELISA (enzyme-linked immunosorbent assay). HMGB1 concentration was assayed by ELISA Kit (ST51011; Tecan, Männedorf, Switzerland) according to the manufacturer's instructions. IL-1 $\beta$ concentration was assayed by ELISA Kit (DKW12-2012-096; Dakewe, Shenzhen, Guangzhou, China) according to the manufacturer's instructions.

Cycloheximide chase assay. HEK293 cells were transfected with plasmids expressing Flag-NLRP3 with or without Myc-YopM, Myc-YopM $\Delta$ N, Myc-YopM C68A. Cells were collected by trypsinization after treatment with cycloheximide $(10 \mu \mathrm{M})$ for the indicated times and lysed for Immunoblotting analysis with anti-Flag antibody. The band intensity of the Immunoblotting result was measured by gel documentation system with the reading normalized as percentage of the initial NLRP3 level (level at time $=0$ ). The percentage was then plotted against time, and the half-life of the NLRP3 protein was calculated as the time required for degradation of $50 \%$ of the protein.

Histopathological scoring. Lung, liver and spleen tissues were fixed in $10 \%$ phosphate-buffered formalin, dehydrated by a tissue processor and embedded in paraffin. Tissues were sectioned using a microtome $(5 \mu \mathrm{m})$ and H\&E stained with an autostainer. Histological scoring of coded slides was evaluated by a single pathologist, blinded to the source of the slides, based on a modified system.

Immunohistochemical (IHC) staining. IHC staining for NLRP3 was performed on the paraffin-embedded tissue microarray. The TMAs were performed on $5 \mu \mathrm{m}$ thick sections. Tissue slides were de-paraffinized and rehydrated through a graded alcohol series. Antigen retrieval was performed by placing the slides in $10 \mathrm{mM}$ sodium citrate buffer ( $\mathrm{pH}$ 6.0) and maintained at a sub-boiling temperature for $10 \mathrm{~min}$. To block non-specific staining, the slides were immersed in 10\% normal goat serum in phosphate-buffered saline (PBS) for $30 \mathrm{~min}$. Then, primary antibody was used overnight at $4{ }^{\circ} \mathrm{C}$ in a humidified chamber. Slides were washed in PBS, followed by secondary antibody for $30 \mathrm{~min}$ at room temperature.

Real-time RT-PCR. RNA was extracted with TRlzol reagent (Invitrogen). cDNA was synthesized with $1 \mu \mathrm{g}$ of total RNA using the Moloney murine leukemia virus reverse transcriptase (Transgen Biotech, Beijing, China) and random primers. Realtime PCR was performed using TransStart Green qPCR SuperMix (Transgen Biotech) and was analyzed on an ABI Prism 7500 analyzer (Applied Biosystems, Waltham, MA, USA). All real-time values were normalized to GAPDH in the same samples. Sequences of the primers are as follows: GAPDH forward primer: $5^{\prime}-A C$ AACTTTGGTATCGTGGAAGG-3'; GAPDH reverse primer: 5'-GCCATCACGCC ACAGTTTC-3'; NRLP3 forward primer: 5'- GATCTTCGCTGCGATCAACAG-3'; NRLP3 reverse primer: 5'- CGTGCATTATCTGAACCCCAC-3'.

Cytotoxicity assay. Lactate dehydrogenase (LDH) content was measured in the aspirated media collected from cells infected after 2 or $6 \mathrm{~h}$ of infection. Samples were run in triplicate using the QuantiChrom kit (BioAssay Syst, Hayward, CA, USA) and the manufacturer's instructions. Percent cytotoxicity was assessed by comparing the amount of LDH in the supernatant to that recovered from control cells that were not infected following lysis by $0.1 \%$ triton X-100.

Animals. Male and female wild-type C57BL/6 mice, ranging from 20-30 g were used for challenging experiments. During challenging with $Y$. pestis strains, mice were maintained in select agent authorized animal biosafety level 3 facilities at Beijing Institute of Biotechnology. All infected mice were monitored regularly by daily weighing and assignment of health scores.

Ethics statement. All animals were handled in strict accordance to the 'Guide for the Care and Use of Laboratory Animals" and the "Principles for the Utilization and Care of Vertebrate Animals", and all animal work was approved by the Institutional Animal Care Committee of Beijing Institute of Biotechnology (protocol number 2012-001-13)

Statistical analysis. All data were presented as average \pm standard error. Two-tailed Student's $t$-test was used for evaluating statistical significance between groups. ${ }^{*} P<0.01$ were considered to be statistically significant.

\section{Conflict of Interest}

The authors declare no conflict of interest.

Acknowledgements. This work was supported in part by the National Natural Science Foundation of China (31170029, 31471325, 31470850, 81401641, 81671973, 31270911,31571424 , and 31670761). The funders had no role in study design, data collection and analysis, decision to publish, or preparation of the manuscript.

1. Broz $P$, Monack DM. Molecular mechanisms of inflammasome activation during microbial infections. Immunol Rev 2011; 243: 174-190.

2. Bryan NB, Dorfleutner A, Rojanasakul Y, Stehlik C. Activation of inflammasomes requires intracellular redistribution of the apoptotic speck-like protein containing a caspase recruitment domain. J Immunol 2009; 182: 3173-3182.

3. Martinon F, Tschopp J. Inflammatory caspases and inflammasomes: master switches of inflammation. Cell Death Differ 2007: 14: 10-22.

4. Dinarello CA. Interleukin-1 beta, interleukin-18, and the interleukin-1 beta converting enzyme. Ann N Y Acad Sci 1998; 856: 1-11.

5. Franchi L, Eigenbrod T, Munoz-Planillo R, Nunez G. The inflammasome: a caspase-1activation platform that regulates immune responses and disease pathogenesis. Nat Immunol 2009; 10: 241-247.

6. Stehlik C, Lee SH, Dorfleutner A, Stassinopoulos A, Sagara J, Reed JC. Apoptosisassociated speck-like protein containing a caspase recruitment domain is a regulator of procaspase-1 activation. J Immunol 2003; 171: 6154-6163.

7. Stehlik C. The PYRIN domain in signal transduction. Curr Protein Peptide Sci 2007; 8 : 293-310.

8. Duncan JA, Bergstralh DT, Wang Y, Willingham SB, Ye Z, Zimmermann AG et al. Cryopyrin NALP3 binds ATP/dATP, is an ATPase, and requires ATP binding to mediate inflammatory signaling. Proc Natl Acad Sci USA 2007; 104: 8041-8046. 
9. Faustin B, Lartigue L, Bruey JM, Luciano F, Sergienko E, Bailly-Maitre B et al. Reconstituted NALP1 inflammasome reveals two-step mechanism of caspase-1 activation. Mol Cell 2007; 25: 713-724.

10. Bergsbaken T, Fink SL, Cookson BT. Pyroptosis: host cell death and inflammation. Nat Rev Microbiol 2009; 7: 99-109.

11. Ghiringhelli F, Apetoh L, Tesniere A, Aymeric L, Ma Y, Ortiz C et al. Activation of the NLRP3 inflammasome in dendritic cells induces IL-1beta-dependent adaptive immunity against tumors. Nat Med 2009; 15: 1170-1178.

12. Mariathasan S, Newton K, Monack DM, Vucic D, French DM, Lee WP et al. Differential activation of the inflammasome by caspase-1 adaptors ASC and Ipaf. Nature 2004; 430 : 213-218.

13. Yamamoto M, Yaginuma K, Tsutsui H, Sagara J, Guan X, Seki E et al. ASC is essential for LPS-induced activation of procaspase-1 independently of TLR-associated signal adaptor molecules. Genes Cells 2004; 9: 1055-1067.

14. Franchi L, Park JH, Shaw MH, Marina-Garcia N, Chen G, Kim YG et al. Intracellular NOD-like receptors in innate immunity, infection and disease. Cell Microbiol 2008; 10: 1-8.

15. Fritz JH, Ferrero RL, Philpott DJ, Girardin SE. Nod-like proteins in immunity, inflammation and disease. Nat Immunol 2006; 7: 1250-1257.

16. Wen $C$, Yang X, Yan Z, Zhao M, Yue X, Cheng X et al. Nalp3 inflammasome is activated and required for vascular smooth muscle cell calcification. Int J Cardiol 2013; 168: 2242-2247.

17. Martinon F, Burns K, Tschopp J. The inflammasome: a molecular platform triggering activation of inflammatory caspases and processing of prolL-beta. Mol Cell 2002; 10: 417-426.

18. Yazdi AS, Guarda G, Riteau N, Drexler SK, Tardivel A, Couillin I et al. Nanoparticles activate the NLR pyrin domain containing 3 (Nlrp3) inflammasome and cause pulmonary inflammation through release of IL-1alpha and IL-1beta. Proc Natl Acad Sci USA 2010; 107: 19449-19454.

19. Wong KW, Jacobs WR Jr. Critical role for NLRP3 in necrotic death triggered by Mycobacterium tuberculosis. Cell Microbiol 2011; 13: 1371-1384

20. Coburn B, Sekirov I, Finlay BB. Type III secretion systems and disease. Clin Microbiol Rev 2007; 20: 535-549.

21. Diacovich L, Gorvel JP. Bacterial manipulation of innate immunity to promote infection. Nat Rev Microbiol 2010; 8: 117-128.

22. Gregory SM, Davis BK, West JA, Taxman DJ, Matsuzawa S, Reed JC et al. Discovery of a viral NLR homolog that inhibits the inflammasome. Science 2011; 331: 330-334.

23. Huebener P, Pradere JP, Hernandez C, Gwak GY, Caviglia JM, Mu X et al. The HMGB1/ RAGE axis triggers neutrophil-mediated injury amplification following necrosis. J Clin Invest 2015; 125: 539-550.

24. Ong SP, Lee LM, Leong YF, Ng ML, Chu JJ. Dengue virus infection mediates HMGB1 release from monocytes involving PCAF acetylase complex and induces vascular leakage in endothelial cells. PloS One 2012; 7: e41932.

25. Ulland TK, Ferguson PJ, Sutterwala FS. Evasion of inflammasome activation by microbia pathogens. J Clin Invest 2015; 125: 469-477.

26. Zheng Y, Lilo S, Mena P, Bliska JB. YopJ-induced caspase-1 activation in Yersinia-infected macrophages: independent of apoptosis, linked to necrosis, dispensable for innate host defense. PloS One 2012; 7: e36019.

27. Buchanan SG, Gay NJ. Structural and functional diversity in the leucine-rich repeat family of proteins. Progr Biophys Mol Biol 1996; 65: 1-44.

28. Kobe B, Kajava AV. The leucine-rich repeat as a protein recognition motif. Curr Opin Struct Biol 2001; 11: 725-732.

29. Vieux EF, Barrick D. Deletion of internal structured repeats increases the stability of a leucine-rich repeat protein, YopM. Biophys Chem 2011; 159: 152-161.

30. Evdokimov AG, Anderson DE, Routzahn KM, Waugh DS. Unusual molecular architecture of the Yersinia pestis cytotoxin YopM: a leucine-rich repeat protein with the shortest repeating unit. J Mol Biol 2001; 312: 807-821.

31. Benabdillah R, Mota LJ, Lutzelschwab S, Demoinet E, Cornelis GR. Identification of a nuclear targeting signal in YopM from Yersinia spp. Microb Pathog 2004; 36: 247-261.

32. Kloss E, Barrick D. C-terminal deletion of leucine-rich repeats from YopM reveals a heterogeneous distribution of stability in a cooperatively folded protein. Protein Sci 2009; 18 : 1948-1960.

33. Skrzypek E, Myers-Morales T, Whiteheart SW, Straley SC. Application of a Saccharomyces cerevisiae model to study requirements for trafficking of Yersinia pestis YopM in eucaryotic cells. Infect Immun 2003; 71: 937-947.

34. McDonald C, Vacratsis PO, Bliska JB, Dixon JE. The Yersinia virulence factor YopM forms a novel protein complex with two cellular kinases. J Biol Chem 2003; 278: 18514-18523.

35. McCoy MW, Marre ML, Lesser CF, Mecsas J. The C-terminal tail of Yersinia pseudotuberculosis YopM is critical for interacting with RSK1 and for virulence. Infect Immun 2010; 78: 2584-2598.

36. McPhee JB, Mena P, Bliska JB. Delineation of regions of the Yersinia YopM protein required for interaction with the RSK1 and PRK2 host kinases and their requirement for interleukin-10 production and virulence. Infect Immun 2010; 78: 3529-3539.

37. LaRock CN, Cookson BT. The Yersinia virulence effector YopM binds caspase-1 to arrest inflammasome assembly and processing. Cell Host Microbe 2012; 12: 799-805.

38. Zhu Y, Li H, Hu L, Wang J, Zhou Y, Pang Z et al. Structure of a Shigella effector reveals a new class of ubiquitin ligases. Nat Struct Mol Biol 2008; 15: 1302-1308.
39. Willingham SB, Allen IC, Bergstralh DT, Brickey WJ, Huang MT, Taxman DJ et al. NLRP3 (NALP3, Cryopyrin) facilitates in vivo caspase-1 activation, necrosis, and HMGB1 release via inflammasome-dependent and -independent pathways. J Immunol 2009; 183: 2008-2015.

40. Satoh T, Kambe N, Matsue H. NLRP3 activation induces ASC-dependent programmed necrotic cell death, which leads to neutrophilic inflammation. Cell Death Dis 2013; 4: e644.

41. Yu HB, Finlay BB. The caspase-1 inflammasome: a pilot of innate immune responses. Cell Host Microbe 2008; 4: 198-208.

42. Creagh EM, O'Neill LA. TLRs, NLRs and RLRs: a trinity of pathogen sensors that co-operate in innate immunity. Trends Immunol 2006; 27: 352-357.

43. Poeck H, Bscheider M, Gross O, Finger K, Roth S, Rebsamen M et al. Recognition of RNA virus by RIG-I results in activation of CARD9 and inflammasome signaling for interleukin 1 beta production. Nat Immunol 2010; 11: 63-69.

44. Bauernfeind FG, Horvath G, Stutz A, Alnemri ES, MacDonald K, Speert D et al. Cutting edge: NF-kappaB activating pattern recognition and cytokine receptors license NLRP3 inflammasome activation by regulating NLRP3 expression. J Immunol 2009; 183: 787-791.

45. Latz E, Xiao TS, Stutz A. Activation and regulation of the inflammasomes. Nat Rev Immunol 2013; 13: 397-411.

46. Johnston JB, Barrett JW, Nazarian SH, Goodwin M, Ricciuto D, Wang G et al. A poxvirusencoded pyrin domain protein interacts with ASC-1 to inhibit host inflammatory and apoptotic responses to infection. Immunity 2005; 23: 587-598.

47. Dorfleutner A, Talbott SJ, Bryan NB, Funya KN, Rellick SL, Reed JC et al. A Shope Fibroma virus PYRIN-only protein modulates the host immune response. Virus Genes 2007; 35: 685-694.

48. Gregory SM, Damania B. Inhibition of the inflammasome response by a viral protein that interacts with NLRs. Commun Integr Biol 2011; 4: 416-418.

49. Wang Z, Chua HK, Gusti AA, He F, Fenner B, Manopo I et al. RING-H2 protein WSSV249 from white spot syndrome virus sequesters a shrimp ubiquitin-conjugating enzyme, PvUbc, for viral pathogenesis. J Virol 2005; 79: 8764-8772.

50. Muller AJ, Hoffmann C, Galle M, Van Den Broeke A, Heikenwalder M, Falter L et al. The S. typhimurium effector SopE induces caspase-1 activation in stromal cells to initiate gut inflammation. Cell Host Microbe 2009; 6: 125-136.

51. Willingham SB, Bergstralh DT, O'Connor W, Morrison AC, Taxman DJ, Duncan JA et al. Microbial pathogen-induced necrotic cell death mediated by the inflammasome components CIAS1/cryopyrin/NLRP3 and ASC. Cell Host Microbe 2007; 2: 147-159.

52. Chung LK, Philip NH, Schmidt VA, Koller A, Strowig T, Flavell RA et al. IQGAP1 is important for activation of caspase- 1 in macrophages and is targeted by Yersinia pestis type III effector YopM. mBio 2014; 5: e01402-e01414.

53. Yang H, Ochani M, Li J, Qiang X, Tanovic M, Harris HE et al. Reversing established sepsis with antagonists of endogenous high-mobility group box 1. Proc Natl Acad Sci USA 2004; 101: 296-301.

54. Turk V, Stoka V, Vasiljeva O, Renko M, Sun T, Turk B et al. Cysteine cathepsins: from structure, function and regulation to new frontiers. Biochim Biophys Acta 2012; 1824: 68-88.

55. Pechous RD, Sivaraman V, Price PA, Stasulli NM, Goldman WE. Early host cell targets of Yersinia pestis during primary pneumonic plague. PLOS Pathog 2013; 9: e1003679.

56. Caulfield AJ, Walker ME, Gielda LM, Lathem WW. The Pla protease of Yersinia pestis degrades fas ligand to manipulate host cell death and inflammation. Cell Host Microbe 2014; 15: $424-434$.

57. Song $Y$, Tong Z, Wang J, Wang L, Guo Z, Han Y et al. Complete genome sequence of Yersinia pestis strain 91001, an isolate avirulent to humans. DNA Res 2004; 11: 179-197.

58. Datsenko KA, Wanner BL. One-step inactivation of chromosomal genes in Escherichia coli K-12 using PCR products. Proc Natl Acad Sci USA 2000; 97: 6640-6645.

59. Auerbuch V, Golenbock DT, Isberg RR. Innate immune recognition of Yersinia pseudotuberculosis type III secretion. PLoS Pathog 2009; 5: e1000686.

60. Logsdon LK, Mecsas J. Requirement of the Yersinia pseudotuberculosis effectors YopH and YopE in colonization and persistence in intestinal and lymph tissues. Infect Immun 2003; 71: 4595-4607.

61. Singer AU, Rohde JR, Lam R, Skarina T, Kagan O, Dileo R et al. Structure of the Shigella T3SS effector IpaH defines a new class of E3 ubiquitin ligases. Nat Struct Mol Biol 2008; 15 : 1293-1301.

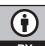

Cell Death and Disease is an open-access journal published by Nature Publishing Group. This work is licensed under a Creative Commons Attribution 4.0 International License. The images or other third party material in this article are included in the article's Creative Commons license, unless indicated otherwise in the credit line; if the material is not included under the Creative Commons license, users will need to obtain permission from the license holder to reproduce the material. To view a copy of this license, visit http://creativecommons.org/licenses/by/4.0/

\section{(C) The Author(s) 2016}

